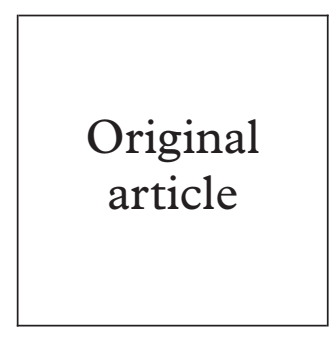

\title{
Homosexual men's HIV related sexual risk behaviour in Scotland
}

\author{
G J Hart, P Flowers, G J Der, J S Frankis
}

Objective: To date, the epidemic of HIV infection in Scotland has been primarily associated with injecting drug use. However, the epidemiology of HIV in Scotland changed in the late 1980s, with homosexual men becoming the largest group at risk of HIV infection and AIDS. Our aim was to describe homosexual men's sexual risk behaviours for HIV infection in a sample of men in Scotland's two largest cities.

Design/setting: Trained sessional research staff administered a short self completed questionnaire, to homosexual men present in all of Glasgow's and Edinburgh's "gay bars," during a 1 month period.

Subjects: A total of 2276 homosexual men participated, with a response rate of $78.5 \%$. Of these, 1245 were contacted in Glasgow and 1031 in Edinburgh.

Main outcome measures: Sociodemographic data, recent (past year) sexual behaviour, information on last occasion of anal intercourse with and without condoms, and sexual health service use.

Results: Anal intercourse is a common behaviour; $75 \%$ of men have had anal intercourse in the past year. A third of our sample report anal intercourse with one partner in the past year, but $42 \%$ have had anal intercourse with multiple partners. Over two thirds of the total population have not had any unprotected anal intercourse (UAI) in the past year and a quarter of the sample have had UAI with one partner only. $8 \%$ report UAI with two or more partners. More men in Edinburgh $(17 \% v 10 \%)$ reported unprotected sex with casual partners only, but more men in Glasgow $(29 \%$ v $20 \%)$ reported UAI with both casual and regular partners $\left(\chi^{2}=12.183 p<0.02\right)$. Multiple logistical regression found that odds of UAI are 30\% lower for men with degree level education and $40 \%$ lower for men who claim to know their own HIV status, whereas they are $40 \%$ higher for those who have been tested for HIV and $48 \%$ higher for infrequent visitors to the "gay scene". Men who have had an STI in the past year are 2.4 times more likely to report UAI than those who have not. Men with a regular partner were significantly more likely to report UAI, as were those who had known their partner for longer, and who claimed to know their partner's antibody status.

Conclusion: On the basis of current sexual risk taking, the epidemic of HIV among homosexual men in Scotland will continue in future years. The data reported here will prove useful both for surveillance of sexual risk taking, and the effectiveness of Scotland-wide and UK-wide HIV prevention efforts among homosexual men.

(Sex Transm Inf 1999;75:242-246)

Keywords: HIV; homosexual men; sexual behaviour; Scotland

\section{Introduction}

Internationally it has been assumed that the Scottish HIV epidemic is limited to injecting drug users and, to a lesser extent, their heterosexual partners; in the widely cited AIDS in the $W_{\text {Wrld }}^{1}$ the only references to Scotland are in this connection. Yet throughout the 1990s, sex between men has been the primary cause of incident HIV infection in the country, with $74 \%$ of new cases in this category, and since 1988 there has been a significant and continuing annual increase in the number of cases in this group. ${ }^{2}$ By December 1996 sex between men was the major mode of HIV transmission in Scotland (51\%), and to June 1997 homosexual men constituted the largest group of AIDS cases across all categories $(39 \%){ }^{3}$ A recent analysis of newly diagnosed HIV infection in homosexual men in Edinburgh suggested that most cases of infection had occurred very recently, with only a minority representing long standing disease. ${ }^{4}$ In this situation there is a pressing need to understand the extent and nature of the current risk behaviour of homosexual men in Scotland, and to improve means by which HIV infection can be prevented if we are to avoid the very high incidence that occurred in injecting drug users in the 1980s.

Previous research on homosexual men in Scotland has been very small scale, ${ }^{5}$ and studies undertaken elsewhere in the United Kingdom have not reported on the sexual behaviour of homosexual men resident in Scotland. ${ }^{67}$ Here we describe homosexual men's sexual risk behaviours for HIV infection in a sample of men representative of bar attendees in Scotland's two largest cities, Glasgow and Edinburgh. We report details of recent sexual risk behaviour, including partner related factors associated with condom use, markers of sexual health service use, such as hepatitis B vaccination and HIV antibody testing, and predictors of unprotected anal intercourse (UAI).

We sought to determine current HIV risk related behaviour in order to assess the need for 
a targeted intervention, and to provide baseline information against which intervention efficacy could be measured in the future. These data will prove useful in monitoring HIV related risk behaviour of homosexual men over time. The study offers a knowledge base for homosexual men's sexual behaviour in Scotland, and contributes to a broader understanding of homosexual men's sexual behaviour in the United Kingdom generally.

\section{Methods}

BAR CENSUS AND SURVEY

The study took place in Glasgow and Edinburgh between December 1995 and November, 1996. Although only 45 miles apart, the two cities are perceived as enjoying quite distinctive social and cultural milieux. Both cities, and the towns and villages between and near them, constitute Scotland's "central belt," in which $75 \%$ of the country's 5 million people live and work; the cities' "gay bars" also attract men from many parts of Scotland.

We took, as a model for our work, elements of a US study ${ }^{8}$ in which great care was taken to identify bars and streets where homosexual men congregate in order to achieve, through time and location sampling, data representative of the gay bar going population. In December 1995 we undertook a census of the number of men attending Glasgow's five gay bars during the course of a week, and repeated this in Edinburgh's five gay bars in October 1996. These censuses suggested that it would be practicable to survey a large population of men in gay bars. Men visiting gay bars in Glasgow in January 1996 and in Edinburgh in November 1996 were approached by trained sessional research staff and asked to complete a short self questionnaire which included demographic data, recent (past year) sexual behaviour, information on last occasion of anal intercourse with and without condoms, and sexual health service use. Bars were surveyed either in the early evening (7.00-9.30 pm) or late evening (9.30-12.00 pm), but no bar was surveyed twice in an evening. Thus, with five bars, two "census" points, and 14 nights, a total of 140 visits were made to bars in the two cities. In Glasgow, 1245 of the 1619 men who were approached $(77 \%)$ participated, and 1031 of the 1295 men (80\%) approached in Edinburgh completed a questionnaire. This gave a total of 2276 men and a response rate of $78.5 \%$, with no significant difference in response rates between the two cities.

\section{DATA ANALYSIS}

Data are reported here both for the population as a whole, and where appropriate by each city. We identify statistically significant differences between Glasgow and Edinburgh on the variables reported wherever these arise. The Pearson $\chi^{2}$ test with a single degree of freedom was used for bivariate comparisons unless otherwise stated and multiple logistic regression was used to produce adjusted odds ratios and to assess their significance.

\section{Results}

DEMOGRAPHIC PROFILE AND RECRUITMENT

Table 1 describes the demographic and recruitment characteristics of men in the study. The age range of the sample was $16-65$ years, with a mean age of 31 , and a median age of 30 (SD 8.52). Over half the sample was in the age range $26-36$, and most were well educated and from the higher socioeconomic groups; 1710 $(77 \%)$ were currently in employment, 217 $(10 \%)$ of men were unemployed, $257(11 \%)$ of men were students, and 39 (2\%) had retired.

Because the study took place in two geographically separate cities, men were clearly differentiated by the bar in which they were recruited and by area postcode. It should be noted that nearly one fifth of the men gave Scottish area postcodes other than Glasgow or Edinburgh. However, there were no significant differences with regard to other demographic characteristics except in relation to social class; more men in Glasgow came from manual social classes $\left(\chi^{2}=15.86, \mathrm{p}<0.0004\right)$. Most men are frequent visitors to their respective cities" "gay scenes," with $87 \%$ attending bars at least twice a month.

\section{RECENT SEXUAL RISK BEHAVIOUR}

This is a sexually active population, as can be seen by the results reported in table 2 . Over three quarters of the men have had two or more partners, and the majority report anal intercourse in the past year; $42 \%$ report anal intercourse with two or more partners in the past year.

Over two thirds of the total population have not had any unprotected anal intercourse in the past year. A quarter of the sample had had unprotected intercourse with one partner only, but $8 \%$ report UAI with two or more partners.

Table 1 Demographic and recruitment characteristics

\begin{tabular}{|c|c|c|c|}
\hline Description & $\begin{array}{l}\text { Glasgow } \\
(\%)\end{array}$ & $\begin{array}{l}\text { Edinburgh } \\
(\%)\end{array}$ & $\begin{array}{l}\text { Total } \\
(\%)\end{array}$ \\
\hline Age (years) & $\mathrm{n}=1230$ & $\mathrm{n}=1020$ & $\mathrm{n}=2250$ \\
\hline $16-25$ & 27 & 28 & 28 \\
\hline $26-30$ & 27 & 24 & 26 \\
\hline $31-36$ & 24 & 22 & 23 \\
\hline 37 or older & 22 & 26 & 24 \\
\hline Social class & $\mathrm{n}=1052$ & $\mathrm{n}=877$ & $\mathrm{n}=1929$ \\
\hline I and II & 53 & 51 & 52 \\
\hline III $\mathrm{N}$ and III $\mathrm{M}$ & 32) & 39 & 35 \\
\hline IV and V & 15) & 11 & 13 \\
\hline \multicolumn{4}{|l|}{ Highest educational } \\
\hline qualification & $\mathrm{n}=1100$ & $\mathrm{n}=920$ & $\mathrm{n}=2021$ \\
\hline Secondary & 30 & 29 & 29 \\
\hline Further/vocational & 33 & 32 & 33 \\
\hline \multicolumn{4}{|l|}{ Degree/postgraduate } \\
\hline qualification & 37 & 39 & 38 \\
\hline Area postcode & $\mathrm{n}=1204$ & $\mathrm{n}=955$ & $\mathrm{n}=2159$ \\
\hline Glasgow & 71 & 4 & 41 \\
\hline Edinburgh & 3 & 77 & 36 \\
\hline Rest of Scotland & 21 & 12 & 17 \\
\hline Rest of UK & 5 & 7 & 6 \\
\hline Bar in which recruited & $\mathrm{n}=1239$ & $\mathrm{n}=1014$ & \\
\hline A & 33 & 34 & \\
\hline B & 19 & 23 & \\
\hline C & 17 & 19 & \\
\hline $\mathrm{D}$ & 16 & 18 & \\
\hline $\mathrm{E}$ & 15 & 7 & \\
\hline \multicolumn{4}{|l|}{ Frequency of visits to } \\
\hline "gay scene" & $\mathrm{n}=1244$ & $\mathrm{n}=1010$ & $\mathrm{n}=2234$ \\
\hline$<1$ per month & 2 & 3 & 3 \\
\hline 1 per month & 11 & 12 & 11 \\
\hline 2-3 per month & 31 & 30 & 31 \\
\hline $1-2$ per week & 40 & 42 & 41 \\
\hline 4-5 per week & 16 & 14 & 15 \\
\hline
\end{tabular}


Table 2 Sexual behaviour in the past year Glasgow and Edinburgh samples combined $(n=2223)$

\begin{tabular}{lll}
\hline & \multicolumn{2}{c}{ Total } \\
\cline { 2 - 3 } Sexual behaviour & $n$ & $\%$ \\
\hline Number of partners & & \\
None & 57 & 3 \\
One & 468 & 21 \\
$2-5$ & 704 & 32 \\
6 or more & 991 & 45 \\
Total & 2220 & \\
Number of anal intercourse partners & \\
None & 563 & 25 \\
One & 736 & 33 \\
$2-5$ & 636 & 29 \\
6 or more & 288 & 13 \\
Total & 2223 & \\
Unprotected anal intercourse partners & 68 \\
None & 1496 & 68 \\
One & 528 & 24 \\
$2-5$ & 152 & 7 \\
6 or more & 31 & 1 \\
Total & 2207 & \\
Partner type (unprotected sex) & \\
Regular & 396 & 62 \\
Casual & 81 & 13 \\
Regular and casual & 160 & 25 \\
Total & 637 & \\
\hline
\end{tabular}

Of those reporting unprotected sex, approximately two thirds maintain that this occurred solely with regular partners, a further quarter reported this has occurred with both regular and casual partners, and approximately one in eight men in this group reported that UAI occurred with casual partners only. This means that of all the men in our survey, $18 \%$ report UAI with regular partners only, $7 \%$ had done so with both regular and casual partners, and almost $4 \%$ of the total sample reported UAI with casual partners only.

There were significant differences between men in Edinburgh and Glasgow in terms of the type of partner with whom they report having engaged in unprotected anal intercourse. More men in Edinburgh (17\% v 10\%) reported unprotected sex with casual partners only, but more men in Glasgow (29\% v 20\%) reported UAI with both casual and regular partners $\left(\chi^{2}\right.$ $=12.183 \mathrm{p}<0.02$ ).

We compared younger men (16-25 years) with older men $(26+)$. Younger men were significantly more likely to report more sexual partners in the past year $\left(\chi^{2}=11.712\right.$, $\mathrm{p}<0.009)$, more anal sexual partners in the past

Table 3 Partner related factors associated with last occasion of protected and unprotected anal intercourse, for men who reported some anal intercourse in past year

\begin{tabular}{|c|c|c|c|c|c|}
\hline \multirow[b]{2}{*}{ Context } & \multicolumn{2}{|c|}{ Protected (condom) } & \multicolumn{2}{|c|}{ Unprotected } & \multirow[b]{2}{*}{$\chi^{2}, p$ value } \\
\hline & $n$ & $\%$ & $n$ & $\%$ & \\
\hline \multicolumn{6}{|l|}{ Partner type } \\
\hline Regular romantic & 664 & 45 & 463 & 64 & \\
\hline New romantic & 172 & 12 & 50 & 7 & 82.46 \\
\hline Regular, just sex & 173 & 12 & 66 & 9 & $<0.00001$ \\
\hline One night stand & 387 & 26 & 106 & 15 & \\
\hline Anonymous & 81 & 5 & 38 & 5 & \\
\hline Total & 1477 & & 723 & & \\
\hline \multicolumn{6}{|l|}{ Knowledge of own HIV status } \\
\hline Knew own HIV status & 929 & 62 & 383 & 64 & 0.57 \\
\hline Did not know own HIV status & 573 & 38 & 219 & 36 & $>0.05$ \\
\hline Total & 1502 & & 602 & & \\
\hline \multicolumn{6}{|c|}{ Knowledge of partner's HIV status } \\
\hline Knew his HIV status & 609 & 41 & 328 & 55 & 32.91 \\
\hline Did not know his HIV status & 867 & 59 & 267 & 45 & $<0.00001$ \\
\hline Total & 1476 & & 595 & & \\
\hline $\begin{array}{l}\text { Mean length of acquaintance } \\
\text { (months) }\end{array}$ & 9.2 & & 13.8 & & $<0.001$ \\
\hline
\end{tabular}

year $\left(\chi^{2}=19.833, \mathrm{p}<0.0002\right)$, and more unprotected anal sexual partners in the past year $\left(\chi^{2}=16.004, p<0.002\right)$.

In terms of other demographic factors, postcode was not associated with UAI although social class was. A greater proportion of men from manual social classes $(35 \%)$ reported UAI in the past year compared with men from non-manual social classes $(30.5 \%)\left(\chi^{2}=4.822\right.$, $\mathrm{p}<0.03)$. Similarly there was a significant association between level of education and risk, in which those with higher educational qualifications were less likely to report UAI $\left(\chi^{2}=\right.$ 60.067, p<0.004).

PARTNER RELATED FACTORS ASSOCIATED WITH ANAL INTERCOURSE

We asked men who reported anal intercourse in the past year to describe features of the last occasion they used a condom during intercourse, and the last occasion when no condom was used during this period. Men could complete either or both of these questions, depending on their sexual behaviour in the preceding year. These data are reported in table 3. Partner type varies when men report the last episode of unprotected versus protected anal intercourse. The last episode of UAI is most likely to have occurred with a regular romantic partner $(64 \%)$ whereas most protected episodes (55\%) occurred with other partner types. However, $27 \%$ of episodes of UAI were with non-regular partners, including new romantic partnerships, one night stands, and anonymous contacts. When analysis was restricted to only men who reported details of both unprotected and protected sex in the past year, this pattern of significant differences remained $\left(\chi^{2}=20.79, p<0.001\right)$. Men were equally likely to report "knowing" their own HIV antibody status in protected and unprotected encounters. However, when it came to knowing their partner's HIV status, on the occasion of last using condoms, men were more likely to say they did not know their partner's status, compared with the last occasion of UAI, when more men knew their partner's status. Men describing their partner, on the last occasion of anal intercourse without a condom, reported knowing this man for a longer period of time than men reporting protected anal intercourse.

EXPERIENCE OF STIS, HIV TESTING, AND SEXUAL BEHAVIOUR

Table 4 demonstrates that there are significant differences between Glasgow and Edinburgh in terms of reported sexual health, with more men in Edinburgh reporting both lifetime and recent sexually transmitted infections. Edinburgh men were also more likely to have been vaccinated against hepatitis $B$ and tested for HIV, with a greater proportion of Edinburgh men reporting testing more recently.

For the subsample of men who reported some anal intercourse in the past year, we also compared reported knowledge of HIV status (asked in relation to the last occasion of anal intercourse) with reports of HIV testing. Of 917 men who reported knowing their status on 
Table 4 Sexual health service use

\begin{tabular}{llllll}
\hline Experience of health services & $\begin{array}{l}\text { Glasgow } \\
n(\%)\end{array}$ & $\begin{array}{l}\text { Edinburgh } \\
n(\%)\end{array}$ & $\begin{array}{l}\text { Total } \\
n(\%)\end{array}$ & $\chi^{2}$ & $p$ Value \\
\hline $\begin{array}{l}\text { Lifetime history of STI } \\
\text { STI in past year }\end{array}$ & $390(32)$ & $420(41)$ & $810(36)$ & 21.909 & $<0.00001$ \\
Vaccination against hepatitis B & $116(9)$ & $135(13)$ & $251(11)$ & 8.404 & $<0.004$ \\
HIV antibody tested: & $538(44)$ & $535(53)$ & $1073(48)$ & 18.678 & $<0.00003$ \\
$\begin{array}{l}\text { Date of HIV antibody test: } \\
\text { 1985-87 }\end{array}$ & $24(4)$ & $21(4)$ & $45(4)$ & 10.059 & $<0.018$ \\
$1988-90$ & $55(10)$ & $35(7)$ & $90(8)$ & & $90(8)$ \\
$1991-3$ & $101(18)$ & $76(14)$ & $177(16)$ & & $177(16)$ \\
$1994-7$ & $369(67)$ & $408(76)$ & $777(71)$ & & $777(71)$ \\
\hline
\end{tabular}

Table 5 Adjusted and unadjusted odds ratios of factors predicting unprotected anal intercourse in past year

\begin{tabular}{|c|c|c|c|c|c|}
\hline & \multicolumn{3}{|l|}{ Unadjusted } & \multicolumn{2}{|c|}{ Multivariate } \\
\hline & Odds ratio & $95 \% C I$ & $n$ & Odds ratio & $95 \% C I$ \\
\hline \multicolumn{6}{|l|}{ Sociodemographic variables } \\
\hline Aged over 26 & 0.83 & $0.70-1.07$ & 1628 & & \\
\hline Manual social class & 1.25 & $0.99-1.57$ & 1414 & & \\
\hline Unemployed & $1.60^{\star \star}$ & $1.14-2.22$ & 1616 & & \\
\hline Degree level education & $0.70^{\star \star \star}$ & $0.56-0.87$ & 1471 & $0.71^{\star \star}$ & $0.54-0.92$ \\
\hline Infrequent visitor to the "gay scene" & $1.61^{\star \star}$ & $1.20-2.16$ & 1615 & $1.48^{\star \star}$ & $1.00-2.18$ \\
\hline Ever had an STI & $1.29^{\star}$ & $1.06-1.58$ & 1625 & & \\
\hline STI in past year & $1.71^{\star \star \star}$ & $1.28-2.30$ & 1620 & $2.42^{\star \star \star}$ & $1.65-3.55$ \\
\hline Ever tested for HIV & $1.35^{\star \star}$ & $1.11-1.64$ & 1609 & $1.40^{\star \star}$ & $1.04-1.87$ \\
\hline \multicolumn{6}{|l|}{ Partner variables } \\
\hline Regular romantic partner & $1.00^{\star \star \star}$ & & 1493 & $1.00^{\star \star \star}$ & \\
\hline New romantic partner & 0.38 & $0.26-0.55$ & & 0.41 & $0.23-0.71$ \\
\hline Regular partner, just sex & 0.50 & $0.35-0.72$ & & 0.45 & $0.29-0.71$ \\
\hline One night stand & 0.36 & $0.27-0.48$ & & 0.63 & $0.41-0.97$ \\
\hline Anonymous partner & 0.82 & $0.51-1.33$ & & 1.60 & $0.82-3.10$ \\
\hline Length of acquaintance (months) & $1.04^{\star \star \star}$ & $1.03-1.05$ & 1380 & $1.03^{\star \star \star}$ & $1.02-1.05$ \\
\hline Knew partner's HIV status & $2.01^{\star \star \star}$ & $1.60-2.50$ & 1373 & $2.08^{\star \star}$ & $1.46-2.98$ \\
\hline Knew own HIV status & 1.23 & $0.98-1.54$ & 1388 & $0.61^{\star \star}$ & $0.42-0.88$ \\
\hline
\end{tabular}

${ }^{\star} \mathrm{p}<0.05,{ }^{\star \star} \mathrm{p}<0.01,{ }^{\star \star \star} \mathrm{p}<0.001$.

the last occasion of having protected sex, 252 $(28 \%)$ said they had not had an HIV antibody test. Similarly, of 380 men who reported knowing their status on the last occasion of having unprotected sex, 99 (26\%) did not report ever having had an HIV antibody test. Thus, knowledge of antibody status was not always corroborated by HIV antibody testing.

FACTORS ASSOCIATED WITH UNPROTECTED ANAL INTERCOURSE

Taking the subsample of 1660 men who reported some anal intercourse in the past year we calculated the unadjusted and adjusted odds ratios for factors associated with unprotected versus protected anal intercourse (table 5). All the variables listed in the table were entered into multiple logistic regression: adjusted odds ratios are given only for those that remained significant. We tested for two way interactions, and a significant interaction between degree level education and ever having had an HIV test was found $\left(\chi^{2}=6.05\right.$, $\mathrm{p}<0.014)$. For the subsample of men who reported some anal intercourse in the past year, younger age and manual social class were no longer significantly associated with UAI. After adjustment, unemployment and ever having had an STI were no longer significant. The odds of UAI were significantly higher for men who were infrequent visitors to the homosexual scene, reported an STI in the past year, and had been tested for HIV. Men who knew their partner's HIV status on the last occasion of anal intercourse and had known their partner for longer were more likely to report UAI, though knowing one's own status was associ- ated with protected anal intercourse. Men with a regular romantic partner were most likely to report UAI, though the apparently high odds of UAI with an anonymous partner should be treated with some caution as they are based on relatively small numbers and thus have a wide confidence interval. Men with degree level education have significantly lower odds of UAI, with the interaction between degree level education and HIV testing showing the lowest odds to be among degree educated men who had never had an HIV test.

\section{Discussion}

This is the first large scale study of homosexual men's sexual behaviour in Scotland, and the largest cross sectional, community based study of homosexual men in the United Kingdom using time and location sampling. The study provides further evidence that this sampling strategy can achieve high response rates. ${ }^{8}$ This is in the absence of data from census tracts on never married men $^{9}$ or large scale representative samples of the sexually active male homosexual population. ${ }^{10}$

As with other recent studies from the United Kingdom, ${ }^{71-13}$ it is clear that most men report consistent safer sex during the past year, and men in Glasgow and Edinburgh report comparable patterns of sexual behaviour with their counterparts elsewhere in the United Kingdom. However, it remains the case that nearly a third of men report unprotected anal intercourse in the past year.

There is now substantial literature from the late $1980 \mathrm{~s}^{14}{ }^{15}$ and early $1990 \mathrm{~s}^{611}$ which identifies partner type as significant in determining whether anal intercourse is protected or unprotected. We find that unprotected sex is more likely to occur with a partner described as regular, whose HIV status is reportedly known, and with whom one has been acquainted for longer. Issues of love, intimacy, and trust are central to and develop during relationships, but within regular relationships this can result in non-use of condoms. ${ }^{16}$ This suggests that there may be a role for HIV prevention efforts to be directed to couples, and attempts made to engage with the sexual dyad as well as individual men. ${ }^{17}$

There is continuing interest in the concept of "negotiated safety," in which men in regular relationships where both partners are of concordant antibody status can explicitly agree not to use condoms within the relationship, while maintaining safer sex outside the relationship. ${ }^{18}$ Here we found that over a quarter of men who reportedly knew their HIV antibody status had not in fact had an HIV test. Elsewhere we have reported that only $22 \%$ of men reporting UAI with a regular partner have been HIV antibody tested and are aware of their partner's antibody status. ${ }^{19}$

Levels of UAI with casual partners are similar in both cities. That nearly one in 10 men reports two or more unprotected anal intercourse partners in the past year must be a cause of significant public health and health promotion concern. The long standing message emphasising the importance of safer sex must 
still be promoted; given that this was a bar recruited population this is a promising context in which targeted efforts should be made.

The higher levels of STIs reported in Edinburgh could be related to disassortative sexual mixing, ${ }^{20}$ given the city's popularity as a tourist destination. If men with STIs present for treatment at sexual health clinics they are more likely than others to be offered hepatitis B vaccination and HIV antibody testing; this may in part explain higher levels of take up of these services in Edinburgh. Nevertheless, compared with other cities in the United Kingdom, vaccination against hepatitis B in both Glasgow and Edinburgh is low. ${ }^{11}$

Levels of HIV testing among homosexual men in this sample are low. ${ }^{21}{ }^{22}$ Men who had not been tested and untested men with degree level education were less likely to report UAI. This may reflect realistic assessment of lower levels of risk behaviour, and is supported by recent work by Hays et $a l,{ }^{9}$ in which untested men in San Francisco reported lower levels of risk. However, it is also clear from Goldberg et $a l^{23}$ that many men who are HIV positive in Scotland are unaware of their HIV status. Increased availability of and encouragement to seek HIV antibody testing should be considered.

Much debate has surrounded the issue of whether young men are at increased risk, ${ }^{15} 24$ though there is little doubt that in the United States young men display high levels of risk behaviour. ${ }^{9}{ }^{25}$ In contrast with other studies in the United Kingdom, ${ }^{11}{ }^{15}$ we found that young men report more partners, more anal partners, and more unprotected anal partners than older men.

Homosexual men currently represent the largest group in Scotland both in terms of incident HIV infection and AIDS cases. ${ }^{323}$ The information reported here offers further support for our view that the epidemic of HIV among homosexual men in Scotland will continue in future years because the risk behaviours necessary for high incidence are in place. The data reported here were collected as part of research to determine the need for novel sexual health promotion interventions for homosexual men in Glasgow and Edinburgh. Future papers will report our evaluation of the effectiveness of this intervention.

This research was funded by the UK Medical Research Council. We would like to thank the Greater Glasgow Health Board for contributing to the research costs of this study, and thank for contributing to the research costs of this study, and thank
clerical and support staff at the MRC Medical Sociology Unit; clerical and support staff at the MRC Medical Sociology Unit; project. Sessional research staff for the study came from a range project. Sessional research staff for the study came from a range
of Scottish homosexual organisations and we thank them for their efforts. The study would not have been possible without the full cooperation and commitment of bar staff and their clientele in Glasgow and Edinburgh.
Sponsorship: UK Medical Research Council and Greater Glasgow Health Board, Scotland.

Contributors: GJ Hart designed and supervised the study, collected data, directed analysis, and wrote the paper; P Flowers contributed to the design of the study, collected data, undertook data analysis, contributed to the writing of the paper; GJ Der undertook data analysis, including multiple logistic regression, and contributed to the writing of the paper; J Frankis undertook data analysis, including multiple logistic regression, and contributed to the writing and resubmission of the paper.

1 Mann M, Tarantola DJM, Netter TW. AIDS in the world. Cambridge, MA: Harvard University Press, 1992.

2 ANSWER. HIV in Scotland; annual review to 31 December 1995. AM-19, no 96/04, 1996.

3 PHLS/SCIEH. AIDS/HIV quarterly surveillance tables: PHLS/SCIEH. AIDS/HIV quarterly surveillance tables:
UK data to end June 1997. Public Health Laboratory Service/Scottish Centre for Infection and Environmental Health 1997;36:97/2

4 Gorman D, Willocks L, McMillan A. HIV seroconversions among gay men in Lothian, 1993-1995. ANSWER 1996;11 (AM-29): 1-4

5 Gruer LD, Lule. Sexual behaviour and the use of condoms by men attending gay bars and clubs in Glasgow and Edinburgh. Int 7 STD AIDS 1993;4:95-8.

6 Hickson F, Weatherburn P, Davies P, et al. The gay men's sex survey at Pride '93. London: Project Sigma/GMFA, 1993.

7 Hickson F, Reid D, Davies P, et al. No aggregate change in homosexual HIV risk behaviour among gay men attending the Gay Pride festivals, United Kingdom, 1993-1995. AIDS 1996;10:771-4.

8 Lemp GF, Hirowza AM, Givertz D, et al. Seroprevalence of HIV and risk behaviours among young homosexual and bisexual men: the San Francisco/Berkeley young men's survey. FAMA 1994;242:449-54.

9 Hays R, Paul J, Ekstrand M, et al. Actual versus perceived HIV status, sexual behaviors and predictors of unprotected sex among young gay and bisexual men who identify as
HIV-negative, HIV-positive and untested. AIDS 1997, 11:14995-1502.

10 Johnson A, Wadsworth J, Wellings $\mathrm{K}$, et al. Sexual attitudes and lifestyles. Oxford: Blackwell, 1994

11 Hart G, Dawson J, Fitzpatrick R, et al. Risk behaviour, anti $\mathrm{HIV}$ and anti HBc prevalence in clinic and non-clinic samples of gay men in England 1991-2. AIDS 1993;7:863-9.

12 Hope VD, MacArthur C. Safer sex and social class: finding from a study of men using the 'gay scene' in the West Midlands region of the United Kingdom. AIDS Care 1999;10 (in press).

13 Nardone A, Mercey D, Johnson A. Surveillance of sexual behaviour among homosexual men in a central London health authority. Genitourin Med 1997;73:198-202.

14 Fitzpatrick R, Boulton M, Hart G, et al. High risk sexual behaviour and condom use in a sample of homosexual and bisexual men. Health Trends 1989;21:76-9.

15 Davies PM, Weatherburn P, Hunt AJ, et al. The sexual behaviour of young gay men in England and Wales. AIDS Care 1992;4:259-72.

16 McLean J, Boulton M, Brookes M, et al. Regular partners and risky behaviour: why do gay men have unprotected intercourse? AIDS Care 1994;6:331-41.

17 Flowers P, Smith JA, Sheeran P, et al. Health and romance: understanding unprotected sex in relationships between gay men. Br f Health Psychol 1997;2:73-86.

18 Kippax S, Noble J, Prestage G, et al. Sexual negotiation in the AIDS era: negotiated safety revisited. AIDS 1997;11: 191-7.

19 Flowers P. 'Negotiated safety' or risk within relationships? Interpreting reports of unprotected anal intercourse. AIDS IMPACT: Biopsychosocial Aspects of HIV Infection. 3rd InterIMPACT: Biopsychosocial Aspects of HIV Infection. 3rd Inter-
national Conference. Melbourne, Australia, June 1997 national Cor

20 Morris M. Sexual networks and HIV. AIDS 1997;11(suppl A):S209-16

21 Dawson J, Fitzpatrick R, Reeves G, et al. Awareness of sexual partners' HIV status as an influence upon high risk sexual behaviour among gay men. AIDS 1994;8:837-41.

22 Hunt AJ, Davies PM, McManus TJ, et al. HIV Infection in a cohort of homosexual and bisexual men. BMF 1992;305: $561-2$.

23 Goldberg D, Scott G, Weir M, et al. HIV infection among homosexual/bisexual males attending genitourinary clinics in Scotland. Sex Transm Inf 1998;74:185-8.

24 de Wit JBF. The epidemic of HIV among young homosexual de Wit JBF. The epidemic of HIV among
men. AIDS 1996;10((suppl 3)):S21-5.

25 Hays R, Kegeles S, Coates T. High risk-taking among young gay men. AIDS 1990;4:901-7. 